\title{
Effect of Different Media on in vitro Seed Germination and Seedling Development of Cymbidium aloifolium (L.) Sw.
}

\author{
Shreeti Pradhan, Tripti Regmi, Gaurav Parmar and Bijaya Pant \\ Central Department of Botany, Tribhuvan University, Kathmandu \\ e-mail:pant_bijaya@yahoo.com
}

\begin{abstract}
A comparative study on in vitro seed germination and seedling development of Cymbidium aloifolium (L.) Sw., an epiphytic medicinal orchid, was carried out on four different conditions of Murashige and Skoog (MS) and Knudson (KC) medium viz. full, 1/2. 1/4 strength and medium supplemented with 0.5mg/l BAP (benzyl amino purine) and $0.5 \mathrm{mg} / \mathrm{l}$ NAA (Naphthalene acetic acid). Varied response in terms of seed germination, protocorm formation and seedling development was observed on two different media. Medium supplemented with hormones favored optimum condition for the germination (approx. 90\%) of seeds followed by full, $1 / 2$ and $1 / 4$ strength on both MS \& KC media. MS medium supplemented with $0.5 \mathrm{mg} / \mathrm{l} \mathrm{BAP} \mathrm{and} 0.5 \mathrm{mg} / \mathrm{l}$ NAA showed comparatively better response within 7 weeks of culture than other conditions of MS medium as well as KC medium. Based upon the results, it was found that MS medium was more effective than KC medium for germination, protocorm and plantlet formation. The present study has provided useful information that the high concentration of nutrient compounds supplemented with hormones are required for earlier in-vitro germination and plantlet development from immature seeds of C. aloifolium. It could be an important protocol to conserve this important orchid species by establishing an efficient in vitro regeneration system using immature seed culture.
\end{abstract}

Key words: protocorms, medicinal orchid

\section{Introduction}

Orchids are one of the most striking decorative plants all over the world. They are highly priced in the national and international markets because of their enduring and beautiful flowers. They account for $7 \%$ of total flowering plant species which represent one of the most expensive ornamental known today and dominate the international cut flower trade (Rahman et al. 2005). Besides their high ornamental values, orchids are of considerable importance in medicines as well. They have rich contents of alkaloids, glycerides and other useful phytochemicals (Gutierrez 2010, Pant 2011).

Cymbidium aloifolium (L.) Sw. is one of the horticulturally as well as medicinally important epiphytic orchid of Nepal. The plant is reported to have emetic and purgative properties (Das et al. 2008). People use its pseudobulb and leaves for various medicinal purposes. Paste of its parts (pseudobulb and leaves) is used as tonic and used over fractured or dislocated bones. The leaves are also extensively used in the treatment of boils, fever and other inflammatory conditions.

This orchid is highly demanded in floriculture market because of its exquisite highly intricate beautiful flowers. Indiscriminate collections by orchid lovers, habitat destruction and over exploitation for medicinal purposes are the main factors that have threatened the survival of this species. Therefore conservation of this orchid is now a matter of universal concern. Tissue culture technique has been widely used for the in vitro mass propagation of several commercially important orchids (Malabadi et al. 2005). 
Orchid's seeds are very minute, non-endospermic and need mycorrhizal association for germination in nature and require up to 8-10 yrs. for their in vivo growth before reaching reproductive maturity (Deb \& Pongener 2011). This problem can be overcome by tissue culture technique. In vitro culture of orchid seed does not require any fungal association and asymbiotic seed germination can be successfully performed leading to plant regeneration. Asymbiotic seed germination of orchids is greatly influenced by several factors such as developmental stage of embryos, age of green pod and different nutrient media with adjuvant and plant growth regulators (Arditti 1979). Modification of traditional tissue culture technique by adding specific plant growth regulators, activated charcoal, peptone and changing culture condition are reported to enhance germination percentage and subsequent development of protocroms in many orchids (Hossain et al. 2009).

The present research highlighted the best medium and concentration for in vitro seed germination, protocorm and seedling development of $C$. aloifolium. It has generated standardized protocol for propagation and their conservation.

\section{Methodology}

The materials used for the present investigation were the seven month old, immature pods of $C$. aloifolium collected from natural habitat from Hetauda, Nepal.

\section{Surface sterilization of explants}

Immature green pods of $C$. aloifolium were used as explants for the present investigation. Young green pods were first cleaned with detergent and tween 20, and finally washed in running tap for 30 minutes till all the detergent was washed off clearly. After that, green pods were surface sterilized sequentially with $70 \%$ ethyl alcohol (2 min.), $1 \%$ sodium hypochlorite solution (10 min.) and finally rinsed thoroughly three times with sterile distilled water. Chemical surface sterilization process was carried out on laminar airflow cabinet.

\section{Culture medium and incubation}

In the present investigation, full, half and quarter strength of Murashige and Skoog (MS) and
Knudson (KC) medium supplemented with or without plant growth regulators viz. BAP $(0.5 \mathrm{mg} / \mathrm{l})$ and NAA $(0.5 \mathrm{mg} / \mathrm{l})$ were used for in vitro seed germination and seedling development. Basal medium were fortified with $30 \mathrm{~g} / \mathrm{l}$ sucrose and with or without different plant growth regulators like BAP \& NAA (Table 1$)$. Difco bacto agar $(0.8 \% \mathrm{w} / \mathrm{v})$ was used as a gelling agent and $\mathrm{pH}$ of the media was adjusted at 5.8 by using $0.1 \mathrm{~N} \mathrm{NaOH}$ or $\mathrm{HCl}$. Agar was dissolved by boiling the mixture and about 20 $\mathrm{ml}$ of media was dispensed into each culture tube (150 X 25mm, Borosil) and autoclaved at $121^{\mathrm{i}} \mathrm{C}$ for $20 \mathrm{~min}$ at $1.05 \mathrm{~kg} / \mathrm{cm}^{2}$ pressure. All cultures were maintained at $25 \pm 2^{\mathrm{i}} \mathrm{C}$ under 350 -500 lux illumination for 16/8 hrs. (light/dark) photoperiod using white fluorescent tubes (Philips, India).

\section{Seed culture}

Surface sterilized immature green pods were kept on sterilized petri dish containing sterilized filter paper for drying. They were cut longitudinally with the help of sharp sterilized surgical blade. The immature seeds were scooped out with the help of sterilized spatula and transferred to and spread over the surface of different strength of MS and KC medium supplemented with or without combination of NAA and BAP. Sub-culturing was carried out every eight weeks into fresh medium and six replicates were used for each treatment. The initiation and rate of seed germination was recorded every week. The entire experiment was performed in aseptic condition under laminar air flow hood to prevent contamination. The mean value of rate of seed germination was tabulated in Table 1.

\section{Results and Discussion}

Effect of nutritional stress and plant growth regulators on seed germination and seedling development in MS medium

Varied response of $C$. aloifolium seeds cultured on MS medium alone, different strength of MS medium (1/2, \&1/4) and MS medium supplemented with BAP $(0.5 \mathrm{mg} / \mathrm{l})$ and NAA $(0.5 \mathrm{mg} / \mathrm{l})$ was found (Table.1). More than $80 \%$ seeds were germinated in all conditions (Table 1). In MS basal medium, the first visible sign of germination was observed as the swollen yellowish green spherule like protocorm within 10 weeks of primary culture. First leaf primordium was developed in 17 weeks of culture, and by 23 weeks roots were 
developed from the base of the shoot. In 30 weeks of culture, complete seedlings were obtained. Though MS basal medium favored seed germination, the rate of seed germination was less in comparison to MS medium supplemented with BAP $(0.5 \mathrm{mg} / \mathrm{l})$ and NAA $(0.5 \mathrm{mg} / \mathrm{l})$ where the initiation of seed germination was observed within 7 weeks of primary culture and around 98\% seeds were successfully germinated. In this condition, after 10 weeks of culture, protocorms were developed which underwent further differentiation to form complete seedlings. First leaf primordia emerged out in 14 weeks of culture which finally developed into embryonic photosynthetic leaves and root developed in 21 weeks of culture. Within 27 weeks of culture, complete seedlings were obtained.

Hence, in the present study, different strength of MS media (1/2, \& 1/4) were found to be efficient for the germination of immature seeds only up to the protocorm development whereas MS media alone and MS media supplemented with BAP $(0.5 \mathrm{mg} / \mathrm{l})$ and NAA $(0.5 \mathrm{mg} / \mathrm{l})$ was found to be the most suitable culture condition for immature seed germination of C. aloifolium up to seedling development but hormone supplemented media took lesser time for germination, protocorm proliferation and further differentiation of leaf primordia than full strength of hormone free MS medium. Therefore the present study showed that full MS medium supplemented with hormones was the best and followed by hormone free full MS, $1 / 2$ MS and $1 / 4$ MS in which germination started after 10, 12 and 15 weeks of primary culture respectively.

\section{Effect of nutritional stress and plant growth regulators on seed germination and seedling development in Knudson (KC) medium}

Immature seeds of $C$. aloifolium cultured on Knudson (KC) medium alone, different strength of KC medium $(1 / 2, \& 1 / 4)$ and KC medium supplemented with BAP $(0.5 \mathrm{mg} / \mathrm{l})$ and NAA $(0.5 \mathrm{mg} / \mathrm{l})$ showed varied response (Table. 1$)$. Like MS medium, all the culture conditions favored seed germination. Swelling of small yellowish green spherules was the first visible sign of germination on Knudson medium. This was observed within 8 weeks of primary culture on KC medium supplemented with BAP (0.5 mg/l) and NAA (0.5 $\mathrm{mg} / \mathrm{l})$. In this condition, green spherules later turned to large protocorm like bodies within 12 weeks of culture, first leaf and root primordia developed in 17 and 24 weeks of culture respectively and well developed complete seedlings were obtained within 30 weeks of culture whereas hormone free full strength Knudson basal medium took 9 weeks after culture for initiation of seed germination ,13 weeks for PLB's formation, 19 weeks for first leaf primordia, 25 weeks for first root primordia and 31weeks for complete seedling formation. This medium was followed by hormone free $1 / 2$ and $1 / 4$ strength $\mathrm{KC}$ where seed germination started within 10 and 15 weeks of culture respectively (Table 1).

Similar to MS medium, hormone supplemented Knudson medium was found to be better for earlier seed germination and seedling development of $C$. aloifolium than hormone free full, $1 / 2$ and $1 / 4$ strength of Knudson medium.

Table 1. Comparative effect of different strength and growth regulators supplemented MS and KC media on seed germination and seedling growth of $C$. aloifolium

\begin{tabular}{|c|c|c|c|c|c|c|c|c|c|}
\hline \multirow{2}{*}{\multicolumn{2}{|c|}{$\begin{array}{r}\text { Medium different } \\
\text { strength } \\
\text { of } \\
\text { medium }\end{array}$}} & \multicolumn{6}{|c|}{$\begin{array}{l}\text { Plant growth Observation taken in weeks } \\
\text { regulators }\end{array}$} & \multirow{2}{*}{$\begin{array}{c}\text { germination } \\
\text { Seedling }\end{array}$} & \multirow[t]{2}{*}{$\begin{array}{l}(\%) \\
\text { (mean) }\end{array}$} \\
\hline & & (mg/l) & NAA & $\begin{array}{l}\text { Initiation } \\
\text { of } \\
\text { germination }\end{array}$ & $\begin{array}{l}\text { Development } \\
\text { of } \\
\text { protocorms }\end{array}$ & \multicolumn{2}{|c|}{\begin{tabular}{ll}
\multicolumn{2}{l}{ Differentiation of } \\
$\mathbf{1}^{\text {st }}$ leaf & $\mathbf{1}^{\text {st }}$ root \\
primordia & primordia
\end{tabular}} & & \\
\hline MS & 1 & - & - & 10 & 12 & 17 & 23 & 30 & 93.33 \\
\hline & $1 / 2$ & - & - & 12 & 15 & - & - & - & 87.5 \\
\hline & $1 / 4$ & - & - & 15 & 19 & - & - & & 82.5 \\
\hline & 1 & 0.5 & 0.5 & 7 & 10 & $\overline{14}$ & $\overline{21}$ & $\overline{27}$ & 98.33 \\
\hline KC & 1 & _ & _- & 9 & 13 & 19 & 25 & 31 & 87.5 \\
\hline & $1 / 2$ & - & - & 10 & 15 & 22 & - & - & 70.83 \\
\hline & $1 / 4$ & - & - & 15 & 19 & - & - & - & 65.0 \\
\hline & 1 & 0.5 & 0.5 & 8 & 12 & 17 & 24 & 30 & 90.83 \\
\hline
\end{tabular}

Culture conditions: - MS \& KC medium, $25 \pm 2$ ÚC, 32 weeks, 16/8 hrs. photoperiod, 6 replicates were used in each condition. 
Immature seeds of $C$. aloifolium undergo various developmental stages during germination. Germination of orchid seeds is different from other seeds. Orchid seeds are produced in large numbers inside a pod. The seeds are very minute and contain undifferentiated embryos and lacks endosperm. In certain orchids self-pollination is not possible and even if it is possible as in the case of Vanda, one has to wait for 4-6 month for pod development (Fitch 1981).
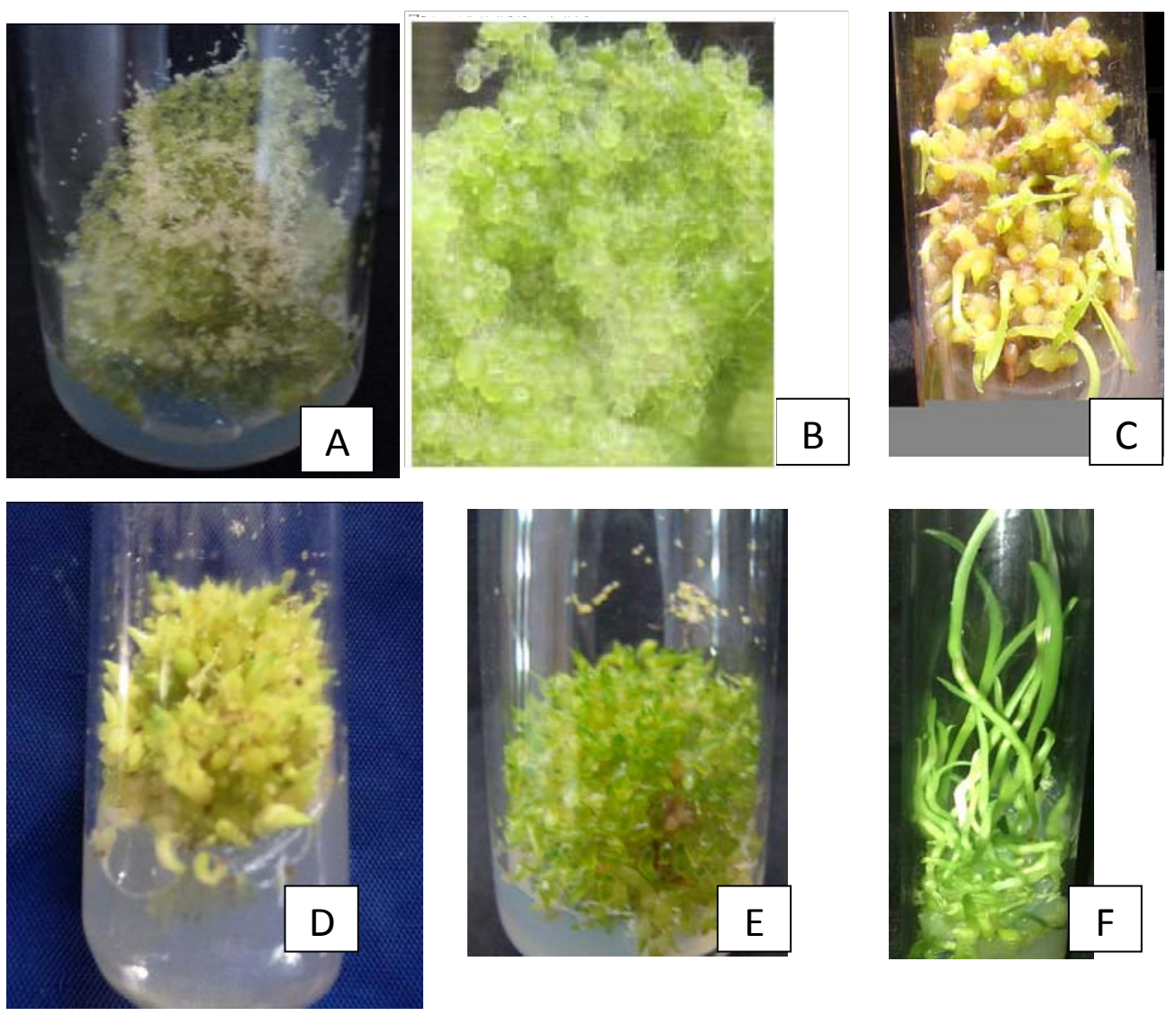

Fig.1. Different stages of in vitro seed germination and seedling development of Cymbidium aloifolium. A. Immature seeds turned into small spherules on $1 / 2$ MS medium, B. Germinating embryos formed PLB's on MS+0.5mg/l BAP+ 0.5mg/ I NAA, C. PLB's with small shoot developed on full strength of Knudson medium, D. Development of small shoot on KC+ 0.5mg/l BAP+ 0.5mg/l NAA, E. Development of small shoot on full strength of MS medium, F. Multiple plantlets formed on MS+0.5mg/l BAP+ 0.5mg/l NAA

In the present investigation, immature green pods were taken for in vitro culture. Due to non-endospermic nature of seed, the germination in nature is a unique phenomenon and requires fungal infection. Germination is much more successful in in vitro condition. Cells of immature seeds first turned into smooth walled globular structures called spherules with sticky hair after seven weeks of seed culture due to the swelling of embryos. This indicates the first visible sign of germination of cultured seeds. Light yellowish cultured seeds first changed into light green and finally to green in color during development of protocorms. Protocorms develop further to give rise to shoot and root without undergoing callus formation in C. aloifolium.

All the testing conditions of both MS and KC media showed seed germination but MS and KC media supplemented with BAP (0.5mg/l) and NAA (0.5mg/l) was the most effective condition for enhancing seed germination and seedling development. Comparative effect of different strength of MS and KC media with 
Shreeti Pradhan et al/Effect of Different Media on in vitro .....

or without BAP \& NAA on seed germination are shown (Table 1). Two media employed in present study were different from one another in their chemical composition. MS medium is highly enriched with macro and micro-elements with different vitamins whereas KC medium contained comparatively low amount of macro and micro elements without vitamins (Hossain et al. 2009). Due to this, maximum percentage of seed germination was observed in different conditions of MS medium rather than Knudson medium as they lack vitamins. There are several reports explaining enhancement of germination and seedling growth and development by vitamins on different orchids. Addition of various vitamins into the medium was reported to be promotive for seed germination and seedling growth of Cymbidium elegans and Coelogyne punctulata (Sharma et al. 1991). Mariat (1949) reported that vitamin-B favored germination and differentiation in Cattleya seedlings. He showed that thiamine, nicotinic acid and biotin were most effective in Cattleya hybrids production. In one another study, Pyridoxine was shown to be essential for chlorophyll synthesis and combination of nicotinic acid and biotin favored better germination of Orchis laxiflora seeds (Mead \& Bulard 1979).

In present investigation, $1 / 2$ and $1 / 4$ strength of both MS and KC medium were not effective for plantlet formation as they have very low amount of macro and micro elements. Full strength of MS and KC medium gave satisfactory result but the time taken for germination and seedling development was quite longer than hormone supplemented MS and $\mathrm{KC}$ medium. In in vitro culture, cytokinins like BAP, BA and Kinetin are generally known to induce both axillary and adventitious shoots formation and auxins like NAA, IAA and IBA for root induction (Jafari et al. 2011). Hormone like BAP was known to enhance the germination frequency of Cypripedium candidum (Depauw et al. 1995), protocorm multiplication and shoot formation in Cymbidium pendulum (Pathak et al. 2001). The synergistic effect of cytokinin and auxin in germination and plantlet development as found in present study has also been reported in Phaius tancarvilleae (Pant et al. 2011), Cymbidium elegans (Pant \& Pradhan 2010) and C. iridiodes (Pongener and Deb 2009).

Protocorms produced in present investigation were globular, hairy and chlorophyllous (green) in all testing conditions of MS medium whereas on KC medium, they were light yellowish in color. The number of protocorms was also lesser on Knudson medium than MS medium but size of protocorms was superior on Knudson medium. Low amount of macro and micro elements of Knudson medium could have been effective for enlargement of protocorms due to nutritional stress but not for increasing their number. Production of large number of protocorms indicates that culture seeds require sufficient amount of nutrients. Thus, the nutrient regime for orchid culture is species specific and no single culture medium is universally applicable for all the orchid species. From above result, it was concluded that MS medium enriched with high concentration of nutritional compounds was suitable for earlier germination, large number of protocorm formation and seedling development rather than Knudson medium. Similar findings were reported in Cleisostoma racemifefum (Deb \& Temjensangb 2007), Malaxix khasiana (Deb \& Temjensangba 2006), Coelogyne suaveolens (Sungkumlong and Deb 2008) where MS medium was shown to be the most suitable medium over other nutrient media.

In the present investigation, a successful attempt was made to compare the in vitro seed germination and their subsequent differentiation of $C$. aloifolium on two media viz. MS and KC. Although MS and KC medium supplemented with BAP $(0.5 \mathrm{mg} / \mathrm{l})$ and NAA (0.5mg/l) showed approximately $90 \%$ seed germination, large number of protocorms and shorter germination period was observed on MS medium supplemented with BAP $(0.5 \mathrm{mg} / \mathrm{l})$ and NAA $(0.5 \mathrm{mg} / \mathrm{l})$. Hormone free full, half and quarter strength of both media took longer time period for germination. Hence in conclusion, MS medium was found to be better than Knudson medium in terms of vigorous growth, production of large protocorms and time requirements especially when medium was supplemented with hormones. This protocol might be useful for selection of best condition for mass propagation and ex- situ conservation of this valuable orchid species.

\section{Acknowledgements}

Authors are grateful to the Central Department of Botany, Tribhuvan University, Kirtipur for providing all laboratory facilities for this investigation and Nepal Academy of Science and Technology (NAST), Khumaltar, Lalitpur, for partial financial support. 


\section{References}

Arditti, J. 1979. Aspects of the physiology of orchids. Advances in Botanical Research 7: 422-638.

Das, P.K., S. Sahoo and S. Bal. 2008. Ethnobotanical studies on orchids of Niyamgiri hillranges. Ethnobot Leaft. 12: 70-78.

Deb, C.R. and A. Pongener. 2012. Studies on the in vitro regenerative competence of aerial roots of two horticultural important Cymbidium species. Journal of Plant Biochemistry and Biotechnology 21: 1-7.

Deb, C.R. and S. Temjensangba. 2006. Effect of different factors on non-symbiotic seed germination, formation of protocorm-like bodies and plantlet morphology of Cleisostoma racemiferum (Lindl.) Garay. Indian Journal of Biotechnology 5:223-228.

Deb, C.R. and Temjensangba. 2006. In vitro propagation of threatened terrestrial orchid. Malaxis khasiana Soland ex. Swartz through immature seed culture. Indian J. Exp. Biol. 44: 762-766.

Deb, C.R. and Temjensangba . 2007. Rapid mass multiplication of Cleisostoma racemiferum (Lindl.) Garay: an endangered orchid. J.Plant. Biol. 34:99-105.

Depauw, M. A, W.R. Remphrey and C.E. Palmer. 1995. The cytokinin preference for in vitro germination and protocorm growth of Cypripedium candidum. Ann. Bot. 75: 267-275.

Fitch, C.H. 1981. All about orchids. Doubleday, Garden City, NY, USA.

Gutierrez, P.M.P. 2010. Orchids: A review of uses in traditional medicine, its phytochemistry and pharmacology. J. Med. Plants Res. 4: 592-638.

Hossain, M.M., M. Sharma and P. Pathak. 2009. Cost effective protocol for in vitro mass propagation of Cymbidium aloifolium (L.) Sw. A medicinally important orchid. Eng. Life Sci. 6: 444-453.

Jafari, N., R.Y. Othman and N. Khalid. 2011. Effect of benzylaminopurine (BAP) pulsing on in vitro shoot multiplication of Musa acuminate (Banana) cv. Berangan. African Journal of Biotechnology 10 (13): 2446-2450.

Malabadi, R.B., S.G. Mulgund and N. Kallappa. 2005. Micropropagation of Dendrobium nobile from shoot tip sections. Journal of Plant Physiology 162: 473-478

Mariat, F. 1949. Action de l'acide nicotinique sur la germination et al de'velopment des embryous de Cattleya. Compt. Rend Acad. Sci. Paris. 229: 1355-1357.

Mead, J. W. and C. Bulard. 1979. Vitamins and nitrogen requirements of Orchis qlaxiflora Lamk. New Phytol. 83: 129-136.

Pathak, P., K.C. Mahant and A. Gupta. 2001. In vitro propagation as an aid to conservation and commercialization of Indian orchids: seed culture. In Orchids: Science and Commerce (Eds. P. Pathak, R. N. Sehgal, N. Shekhar, M. Sharma, A. Sood), Bishen Singh Mahendra Pal Singh, Dehra Dun, India. Pp. 319-362.

Pongener, A. and C.R. Deb. 2009. Asymbiotic culture of immature embryos, masmultiplication of Cymbidium iridioides D. Don. and the role of different factors. International Journal of Pharma and Bio. Sciences 1(1).

Pant, B. 2011. Orchids of Nepal with their medicinal properties. Orchideen Journal 18(3): 92-98.

Pant, B., S. Shrestha and S. Pradhan. 2011. In vitro seed germination and seedling development of Phaius tankervilleae (L'Her.) Blume. Scientific World 9 (9): 50-52.

Pant, B. and S. Pradhan. 2010. Micropropagation of Cymbidium elegans Lindl. through protocorm and shoot tip culture. In: Proceedings of the sixth international plant tissue culture \& biotech. conf., December 3-5, Bangladesh Assoc. Plant Tissue Cult. Biotech. Dhaka, Bangladesh. pp.123-130.

Rahman, A.R.M., M.O. Islam, A.K.M. Azad-ud-doula Prodhan and I. Syoichi. 2005. Effects of arbohydrates on callus growth and callus derived plantlet regeneration in Doritaenopsis orchid. Biotechnology 4: 126-131.

Sharma, S. K., P. Tandon. and R.R. Mishra. 1991. Vitamins as related to axenic seed germination and seedling growth of Cymbidium elegans Lindl. and Coelogyne punctulata Lindl. J. Orchid Soc. India. 5: 25-28.

Sungkumlong and C.R. Deb. 2008. Effects of different factors on immature embryo culture, PLB's differentiation and rapid mass multiplication of Coelogyne suaveolens (Lindl.) Hook. Indian J. Exp. Biol. 46: 243-248 